\title{
A View of the International Conference on Scientific Information
}

"Change is inevitable."

-Benjamin Disraeli

$\mathbf{M}$ OST IF NOT ALL who attended the International Conference on Scientific Information at Washington during November have now returned from that rarefied level of academic discourse, to take up again where they had left off. Yet probably not quite where they had left off. Any advancement of their thought may be taken as a measure of the loss to those who could not attend. The list of academic libraries represented at the conference includes the Australian National University and the University of the Witwatersrand. For the benefit of those academic librarians who could not be present, it might be useful to explain here, in a general way, the work of the ICSI.

To begin with, however, let us agree to the premises upon which the importance of the conference to academic librarians seem to rest. First, that the production, distribution, classification, indexing, and use of scientific literature are intrinsic, and not extraneous, to the academic library. Second, that beneath the jargon of documentation lies the really exciting, but orderly, processes of evolution in librarianship. And third, that the scientists themselves, simply ignoring the sacred cows of the library profession, are in fact asking some of the big questions.

The problem before the ICSI, stated most simply, was the following: What

Mr. Mack is Librarian, Lehigh University.

can government, industry, and the universities do about the exponential growth-rate of scientific literature? Now it is clear that if this growth-rate were linear, at, say one hundred thousand documents annually, there would not have been a conference at all. But because the rate is exponential, and inexorable, special problems have arisen requiring special modes of solution not readily available in the empirical techniques of traditionally trained librarians.

As for the "big questions," two central areas of difficulty seem to have emerged from the week-long discussions: First, what is the fundamental nature of information as such? This kind of query, under the pressure of mathematical and semantic analysis, breaks up into subsidiary questions which only a first-rate logician should try to handle. But it would appear that enough is already known about the problem to enable engineers to try out designs for electronic indexing systems. This is highly tentative at the moment. But it leads directly to the second area of difficulty, namely, how does a scientist use new knowledge? Again there arises a group of related questions. How does a scientist produce information? What are the intellectual processes of reference work? Precisely what is the psychic relationship between one who asks and one who answers a reference question in science? And how, if at all, can that relationship be studied? If we knew, we should probably be training librarians to take a more active, as 
distinct from the normal passive, part in scientific research.

At this point, a wit might say that the documentalists have discovered the human race. Perhaps so! Or it mightindeed can-be said that these big questions are old ones. (They happen also to be unanswered ones.) In any event, it is more than conceivable not only that any sound answers will affect the work of reference librarians in the ways suggested above; but also they could easily involve, say, the overthrow of our traditional hierarchical classification schemes. At least in strictly limited areas, faceted classification seems to offer some possibility of relief. (Dr. Ranganathan was particularly persuasive: his influence abroad is not to be lightly ignored.)

Again, if we knew more about users of scientific information, and more about knowledge itself, we might see changes in many of the media of scientific communication. It is evident that the publishers of our journals, monographs, abstracting services, and compendia are all facing problems of enormous difficulty. A breakthrough in either or both of these questions might mean partial solutions in terms of increased effectiveness and reduction of the drudgery in literature-search.

From what has been said it may naturally be inferred that administrative changes, too, are to be expected. For if both personnel requirements and the materials with which we deal undergo even minute changes as the result of these investigations, we shall be compelled to alter both the type and the structure of our staffs and the ways in which we serve our clientele. And this will profoundly affect our financial problem.

Now, what of the prospects?

Just as surely as the ICSI followed the Royal Society Scientific Information Conference of 1948, there will be fur- ther conferences. Moreover, if one thing is clear, it is that the principal sponsors - governments and industries - will presently begin to adopt policies and practices based upon ideas generated at this conference. At this point, what began as an academic inquiry may end as a factor in a power situation; and the issues will be resolved in appropriate terms.

It seemed apparent to this observer that academic librarians here and abroad have a vital stake in these proceedings, and that many areas of useful research were opened up by this conference. A few projects chosen at random would benefit greatly from the empirical knowledge we have to contribute: (1) If it be supposed, as indeed many do suppose, that the information resources of the world should be organized more rationally, what is the case for coordination as against cooperation? For centralized control as against coordination? (2) What attitudes about the whole problem of bibliographic control in the sciences now prevail among (a) working scientists; (b) academic administrators; (c) professional librarians? (3) Solution of cost problems: e.g., what is the cost of maintaining a subject catalog; what are the commensurate values; is there a better way? (4) Experimental use of faceted classification in a limited area of science. (5) What are the advantages of the Dyson system of chemical notation, as compared to those of other systems, (a) to chemists; (b) to librarians? (6) What does the asker of a scientific reference question really mean when he indicates satisfaction (or dissatisfaction) with the handling of a problem? (7) Investigation of problems in interlibrary communication.

This is all developmental work in which, with no intention of sounding pious, I suggest we can afford to participate. I should add, if I may, that we cannot afford to stand apart. 